\title{
LA GUERRA Y SUS JUSTIFICACIONES SEGÚN EL MATRIMONIO DE GROUCHY-CONDORCET
}

\author{
WAR AND ITS JUSTIFICATIONS IN MARRIAGE DE GROUCHY-CONDORCET
}

\author{
Ricardo Hurtado Simó \\ Universidad de Sevilla (España)
}

Recibido: 20-05-2012

Aceptado: 26-06-2012

\begin{abstract}
Resumen: Este artículo muestra los aspectos más destacados de la visión que tiene el matrimonio De Grouchy-Condorcet respecto a la guerra y sus justificaciones. Mientras que Condorcet piensa que la guerra permite entender la Historia como un camino hacia el progreso y la libertad, De Grouchy defiende la importancia de una teoría de los derechos naturales.
\end{abstract}

Palabras-clave: Guerra, progreso, libertad, razón, simpatía.

\begin{abstract}
This article shows some relevant aspects of the theory about war and its justifications in marriage De Grouchy-Condorcet. Condorcet thinks that war allows understanding History as a way to progress and freedom. De Grouchy writes about the necessity of a theory about natural rights.
\end{abstract}

Key-words: War, progress, freedom, reason, sympathy.

El matrimonio de Sophie De Grouchy con Nicolás de Condorcet duró ocho años, desde 1786 hasta 1794, cuando Condorcet es perseguido por los jacobinos, encarcelado y encontrado muerto en su celda. En estos años no solo nació una hija entre ambos, también brotaron unos vínculos intelectuales muy fuertes, vínculos que fueron reforzados por la ajetreada vida social de ambos y por los acontecimientos históricos acaecidos en Francia durante ese período. La pareja se caracterizaba por tener una relación igualitaria, sin jerarquías y muy enriquecedora para ambos, algo que no podía ser de otra manera tratándose de dos personas tan destacadas.

En los orígenes de la Revolución, entre 1789-1791, el matrimonio formó parte de la izquierda más radical y, así, participaron en las revueltas en los Campos de Marte en julio del 1791, donde la guardia nacional masacró a más de 400 manifestantes. Condorcet era un miembro activo de la Convención 
Republicana que siguió a la caída de la Monarquía, destinada a organizar la nueva República, el nuevo Estado. Tanto Condorcet, por su papel activo en el proceso revolucionario y su interés por la Historia como De Grouchy, firme defensora de la república y una de las pocas ilustradas que sobrevivió a la deriva totalitaria jacobina, realizaron interesantes reflexiones sobre la guerra y la paz que aquí trataremos.

\section{Guerra, paz y progreso en Condorcet.}

Nicolás de Condorcet, en el Bosquejo de un cuadro histórico de los progresos del espíritu humano defiende una visión progresista de la historia y de la humanidad, un progreso que se muestra a través de diferentes etapas históricas o cuadros históricos que culminan en una concepción optimista del futuro, basada en la razón, la ilustración y la ciencia. En este proceso desde los comienzos de la humanidad hasta un futuro esperanzador, Condorcet hará una lectura sobre la guerra llena de contradicciones. Por una parte, considerará la guerra entre semejantes un acto violento fruto del fanatismo, la superstición y el egoísmo. Por otra, entenderá que todo conflicto, por cruento que sea, contiene de una manera u otra la semilla de un tiempo mejor. Como veremos, para el filósofo francés, la guerra conduce, paradójicamente, a la paz. Lo importante es comprender el lento pero inexorable avance de la humanidad entendiendo que las guerras entre Estados son el hilo conductor para descubrir el progreso.

En los comienzos del ser humano, que Condorcet los sitúa en la necesidad de vivir en sociedad, sostiene que la guerra es, en situaciones precarias, una forma de supervivencia. La guerra supone, asimismo, una forma de contacto entre pueblos y culturas diferentes. La introducción de tribus y primitivos ejércitos en territorios desconocidos o la lucha entre aldeas que comparten unos recursos limitados conllevan el conocimiento de técnicas, armas y estrategias militares que ayudan al desarrollo material de la humanidad. Al respecto, en la tercera época que desarrolla en su Bosquejo, Condorcet analiza el progreso de los pueblos agricultores hasta la invención de la escritura alfabética y sostiene que:

"Los progresos de esas artes habrían sido lentos en las naciones aisladas; pero las comunicaciones, todavía precarias, que se establecieron entre ellas aceleraron su marcha. Un perfeccionamiento, un procedimiento nuevo descubierto en un pueblo, pasa a ser común a sus vecinos. Las conquistas, que tantas veces han destruido las artes, comenzaron por extenderlas, y sirvieron a sus perfeccionamientos [...]."1

Para Condorcet, la guerra siempre ha acompañado al ser humano por las diferentes etapas por las que ha transcurrido la Historia. Tanto en la Grecia

[1] CONDORCET, Bosquejo histórico de los progresos del espíritu humano, Madrid, Centro de Estudios Políticos y Constitucionales, 2004, p. 31.

THÉMATA. Revista de Filosofía, Nº 48 julio-diciembre (2013) pp.: 235-243 doi: 10.12795/themata.2013.i48.21 
o la Roma clásicas, en el medievo o en la modernidad, por un motivo u otro las personas han encontrado justificaciones para perseguir o asesinar. Tras esta triste realidad se encuentra el triunfo del oscurantismo y la dictadura sobre la ilustración y la igualdad. La guerra siempre ha sido aliada de la ignorancia y gracias a ella ha encontrado motivos para llevarse a cabo. Así, Condorcet centra su mirada en momentos históricos concretos como la decadencia de Roma. A su juicio, el fin del Imperio romano supuso a la vez el fin del legado humanista clásico; con la caída de Roma también entran en declive las instituciones políticas, las leyes o los ya de por sí escuetos derechos humanos. Los bárbaros que se adentran en sus fronteras solo entienden el lenguaje de la guerra y la violencia. Pero aun así, la paz y el progreso estaban un poco más cerca:

\footnotetext{
"Así, la conquista sometió a cierta parte de Europa a una anarquía tumultuosa, en la que la masa del pueblo gemía bajo la triple tiranía de los reyes, de los jefes guerreros de los sacerdotes, pero que contenía, sin embargo, en su seno los gérmenes de una libertad futura."
}

A partir del Renacimiento, la guerra cambia radicalmente y se extiende hacia las personas inocentes. Afirma Condorcet que no es el anhelo por ampliar las fronteras u obtener recursos lo que mueve ahora a la violencia; es el fanatismo y la religión lo que asola constantemente el mundo conocido, principalmente Europa. El Cristianismo y el Islam se desgajan en numerosas vertientes que luchan en un combate fratricida que hace retroceder el avance de la igualdad y la libertad. Pero de nuevo, el político y matemático ilustrado es capaz de realizar una lectura positiva de una de las etapas más grises de la humanidad. La extensión del fanatismo religioso provoca el rechazo de una minoría intelectual que se niega a tomar parte por ninguno de los contendientes. La emancipación, el librepensamiento y la autonomía dan sus primeros pasos:

"Aquellas guerras, emprendidas a favor de la superstición, sirvieron para destruirla. El espectáculo de muchas religiones acabó por inspirar a los hombres de buen sentido una indiferencia igual respecto a unas creencias igualmente impotentes contra los vicios o las pasiones de los hombres, un desprecio igual por la adhesión igualmente sincera e igualmente obstinada de sus secuaces a unas opiniones contradictorias."

En el cuadro histórico que hace Condorcet, la guerra es, como señalamos anteriormente, el necesario hilo conductor para conocer el proceso de desarrollo desde formas de organización primitivas y violentas hasta un duradero periodo de paz y bienestar. En este proceso, un acontecimiento emerge estableciendo un antes y un después en la manera de entender el conflicto: la independencia de las colonias norteamericanas. Hasta ahora, por optimista que fuese Condorcet, toda guerra estaba motivada por causas perversas y

[2] Ibíd., pp. 74-75.

[3] Ibíd., p. 84.

THÉMATA. Revista de Filosofía, $\mathrm{N}^{\circ} 48$ julio-diciembre (2013) pp.: 235-243 doi: 10.12795/themata.2013.i48.21 
egoístas; era una lucha por conseguir y mantener el poder de manera cruenta. Sin embargo, el nacimiento de los Estados Unidos de América introduce en la guerra una causa racional e incluso loable: la libertad. Condorcet entiende la guerra de independencia norteamericana como un requisito indispensable para el nacimiento del primer Estado libre; es una guerra necesaria para lograr la autonomía y los derechos humanos, en definitiva, para lograr la paz:

\footnotetext{
"América proclamó que la injusticia había roto sus lazos y declaró su independencia.

Entonces, se vio por primera vez a un gran pueblo, liberado de todas sus cadenas, proveerse a sí mismo pacíficamente de la Constitución y de las leyes que creía más idóneas para hacer su felicidad; y como su posición geográfica y su antigua situación política le obligaban a formar una república federativa, se vio cómo preparaba en su seno, a la vez, trece constituciones republicanas, que tenían como base un reconocimiento solemne de los derechos naturales del hombre, y, como primer objetivo, la conservación de esos derechos.”
}

Condorcet escribe estas palabras pocos años después de dicha independencia, justo en el momento en que una nueva Francia empieza a fraguarse; de aquí en adelante, su manera de entender la guerra y la paz cambiará radicalmente.

La última época que analiza en el Bosquejo versa sobre los futuros progresos del espíritu humano. En ese momento por venir, los conflictos irán desapareciendo paulatinamente, de la misma manera que la democracia y la voluntad de los pueblos se irá imponiendo a la de los tiranos. Las guerras ya no serán lideradas por ególatras o fanáticos sino por personas que reclaman derechos. El filósofo francés piensa confiado en un nuevo marco político liderado por Estados liberales y republicanos como los Estados Unidos o la Francia por la que él mismo perdió su vida. También, este planteamiento lo extiende al fin del colonialismo americano y al amanecer de países libres allí donde antes había pueblos gobernados por una metrópolis lejana. La era de la ignorancia y la esclavitud dará paso al fin de la historia como siempre se ha entendido:

"Los pueblos más ilustrados, al recuperar el derecho a disponer por sí mismos de su sangre y de sus riquezas, aprenderán poco a poco a considerar la guerra como el azote más funesto, como el mayor de los crímenes. Y las primeras en desaparecer serán aquellas a las que los pueblos se veían arrastrados por los usurpadores de la soberanía de las naciones en apoyo de unos pretendidos derechos hereditarios. Los pueblos sabrán que no pueden convertirse en conquistadores sin perder su libertad, que unas confederaciones perpetuas son el único medio de mantener su independencia y que deben buscar la seguridad y no la potencia." ${ }^{5}$

He aquí el optimismo condorcetiano en su máximo esplendor: El triunfo de la razón y las luces conllevan irremediablemente al fin de la guerra y, para-

[4] Ibíd., p. 131.

[5] Ibíd., p. 176.

THÉMATA. Revista de Filosofía, Nº48 julio-diciembre (2013) pp.: 235-243 doi: 10.12795/themata.2013.i48.21 
fraseando a Kant, a la paz perpetua, aunque con un significado bien distinto al que le da el pensador de Koningsberg.

\section{Sophie De Grouchy: guerra y paz en la Revolución francesa.}

Sophie De Grouchy es una filósofa francesa que vive entre 1764-1822. De familia aristócrata políticamente conservadora, pronto tuvo interés por la situación política y social de la Francia de su tiempo. Pese a sus orígenes acomodados, De Grouchy sentía especial consideración por la masa sufriente que malvivía con condiciones laborales, educativas y sanitarias muy precarias. Con una gran cultura y conocedora de varios idiomas, pronto se acercó al movimiento ilustrado y a los grupos de intelectuales que defendían la caída de la monarquía. Sus obras más importantes son las Cartas sobre la simpatía, publicadas en 1798, donde, entre otras cuestiones, reflexiona sobre las luces y sombras de la Revolución francesa, y las Cartas de amor a Maillia Garat, en 1800.

Uno de los datos más relevantes de De Grouchy es que es una de las pocas intelectuales que vivió las diferentes etapas del periodo revolucionario: la caída de la monarquía, la constitución de un nuevo Estado, el esplendor y caída jacobino, el Directorio y el ascenso de Napoleón. Irremediablemente, convivió con la guerra y la lucha fratricida; su marido fue perseguido y condenado y muchas de las amistades que frecuentaban su salón filosófico, el Salón de las monedas, la denunciaron y persiguieron, como el propio Robespierre.

Durante este periodo tan triste de su vida, De Grouchy alza la voz contra los tiranos del mundo que oprimen a la población. Para ella, la Francia que proponen los jacobinos no sería más que otra forma de tiranía, caracterizada en este caso por el sometimiento, por la fuerza de un pueblo sobre otro, del fuerte sobre el débil. Ante esta injusticia, solo cabe apelar a la razón, garante de la justicia y de los derechos de los hombres y mujeres sin excepción. La esclavitud y la alienación que suponen los sistemas cerrados son fruto del interés egoísta y el olvido de nuestros semejantes:

“(...) jcomo si la razón pudiera permitir cualquier tipo de poder inicialmente establecido para el interés propio de convertirse en una fuente de tiránicos privilegios y una licencia de impunidad para sus poseedores! Con todo, ¿cómo puede suceder que el sagrado nombre de derecho, que ha sido usado en todas partes para esconder y disfrazar el poder de la fuerza, se convierta en una máscara casi impenetrable ante los ojos de las masas, a pesar del interés que tienen en destrozarlo? Sin duda, durante largo tiempo, aquellos que han gobernado a los hombres han calculado que pueden controlarlos fácilmente oprimiendo la razón bajo el peso de las necesidades; que podían interrumpir los escalafones superiores volviendo la gente hacia ellos y engañando la noble vanidad con bagatelas, y teniendo que temer, por un lado, solo el exceso de desgracia, y por el otro, solo la extensión de las luces." ${ }^{\circ}$

[6] DE GROUCHY, Sophie, Cartas sobre la simpatía, Sevilla, Padilla libros, 2011, pp. 150-151.

THÉMATA. Revista de Filosofía, № 48 julio-diciembre (2013) pp.: 235-243

doi: 10.12795/themata.2013.i48.21 
De Grouchy enfoca la cuestión de la guerra y la paz desde la óptica del derecho que tienen los pueblos a elegir y construir su propio destino, sin injerencias ni dominaciones externas; la pensadora nacida en Meulan reflexiona sobre los motivos que llevan a un conflicto bélico en el contexto del proceso revolucionario francés y los derechos naturales de todos los seres humanos. Como veremos, su concepción de la república francesa es resultado de afirmar que la igualdad y la justicia no son excluyentes, y afectan por igual a mujeres y hombres, ricos y pobres. Así, solo estableciendo como fundamento una teoría de los derechos para todos era posible construir una reivindicación a favor de un Estado democrático extrapolable a otros países del mundo y lograr una paz estable y duradera. A su juicio, la revolución francesa solo será un éxito si se integra a ciertos grupos que tradicionalmente eran excluidos. La paz será posible si se acaba la opresión y triunfa la fraternidad.

Respecto a las líneas fundamentales del pensamiento de De Grouchy sobre la igualdad entre hombres y mujeres, hay que decir que estas cuestiones no radican en una carta concreta de sus Cartas sobre la simpatía, sino que tamizan toda la obra de De Grouchy, aunque es cierto que adquieren mayor peso conforme avanza la exposición de las Cartas, al tratar el sistema legislativo, la política y la sociedad. En primer lugar, es importante recordar el hecho de que es a partir de su matrimonio con nuestra autora cuando Nicolás de Condorcet empieza a publicar sus escritos sobre la igualdad real entre sexos, lo que pone de manifiesto la influencia de De Grouchy al respecto. Asimismo, en su Salón de las monedas, nuestra protagonista organizó numerosas reuniones con miembros destacados del panorama cultural francés y británico para tratar las grandes cuestiones del pensamiento feminista a finales del siglo XVIII. Desde la década de 1780, De Grouchy fue una firme defensora de la activa participación de las mujeres en el proceso revolucionario así como de su derecho a participar en la esfera pública.

Todas estas contribuciones aparecen redactadas en las dos últimas Cartas sobre la simpatía, haciendo especial hincapié en el plano educativo.

En plena coherencia con su teoría "simpática", De Grouchy es consciente de que la cristalización de la igualdad entre hombres y mujeres pasa por un proceso educativo equitativo, que sea capaz de acabar con las diferencias entre sexos. Para Sophie, lograr que las mujeres puedan acceder a una educación completa y no sexista es fundamental para que su inserción en la vida social, política y cultural se convierta en una realidad; pero además, el acceso a una educación adecuada es algo también positivo para los hombres, pues permitiría una mayor compenetración entre ambos sexos, sobre todo en las relaciones familiares y en el matrimonio. Para De Grouchy, la guerra es ante todo violencia y opresión de un grupo sobre otro, es por ello por lo que de acuerdo con su pensamiento se puede entender la desigualdad entre sexos una forma de guerra, un conflicto permanente y aceptado entre dos contendientes muy dispares: 
"La sociedad ha establecido barreras entre los dos sexos (bajo el pretexto de mantener la virtud) que hacen casi impracticable la comprensión mutua de espíritus y corazones que, sin embargo, es necesario para formar uniones virtuosas y duraderas."”

De Grouchy considera fundamental el acceso de las mujeres a la educación; educación es conocimiento, y el conocimiento abre la puerta a la participación en la esfera pública y en el nuevo marco político que se está fraguando. Reivindica que las mujeres salgan de esa forzosa y obligada minoría de edad para superar las barreras de la belleza y la apariencia física a favor de una plena realización a través del conocimiento y el estudio:

"iSi el sexo femenino los ignora o los desdeña, es la mujer la que especialmente se condena, ya que durante solo un momento está blasonada con los más resplandecientes regalos de la naturaleza y, en seguida, esa misma naturaleza se convierte durante mucho tiempo en una cruel madrastra! ¡Por ello es con placeres cotidianos por lo que debe pasar la mitad de su vida y olvidar (si es posible) ese cáliz encantado que la mano del tiempo vuelca para ella a mitad de la carrera!"

Asimismo, la educación también es fundamental para los hombres; al igual que señalaba Condorcet, reducir a los hombres a la ignorancia y al predominio de la fuerza conlleva reforzar la faz violenta, autoritaria y dogmática del ser humano.

Sophie De Grouchy considera que una de las causas fundamentales de guerra y violencia es la exclusión de ciertos grupos por motivos sociales y económicos. En este punto, la autora seguirá muy de cerca las posiciones de J.J. Rousseau principalmente en su Discurso sobre el origen y fundamentos de la desigualdad entre los hombres pero será mucho más combativa que Condorcet. Iniciará su defensa al respecto señalando la enorme desproporción existente entre la desigualdad natural, propia y constitutiva de los seres humanos, y la desigualdad social, que tiene su origen en la vida en sociedad y está promovida por intereses perversos, egoísmo y abuso de poder. En concreto, denunciará la situación del campesinado francés y el emergente proletariado que empieza a situarse a las afueras de las grandes ciudades, colectivos ambos, sometidos a la voluntad de los grandes terratenientes y propietarios. Esta clase social emergente, de buena ley reclamará un cambio radical en su situación, con el consiguiente conflicto con los grupos dirigentes.

Frente a esta situación, De Grouchy abogará por una redistribución de las riquezas en base al derecho que tienen todos los seres humanos a poseer un terreno, una propiedad que sea la base de sus recursos vitales; asimismo, reclama un menor intervencionismo del Estado en los movimientos del mercado para favorecer la iniciativa privada de los pequeños propietarios.

[7] Ibíd., 126-127.

[8] Ibíd., p. 184.

THÉMATA. Revista de Filosofía, No$^{\circ} 48$ julio-diciembre (2013) pp.: 235-243 doi: 10.12795/themata.2013.i48.21 
Uno de los grandes caballos de batalla de De Grouchy en este punto será su convencimiento de la necesidad de reformar completamente el sistema legislativo. Considera que las leyes, con el paso del tiempo, se han convertido en el instrumento más acabado y perfecto para asentar la hegemonía de unos pocos sobre el resto; son una forma subliminal de hacer la guerra y de subyugar a las personas. Las leyes permiten la perpetuación de los poderosos en los cargos más relevantes de una nación haciendo caso omiso o castigando con laxitud sus irregularidades. Ubicando esta cuestión en el contexto histórico francés, a su juicio, las leyes eran perversas y corruptas bajo la monarquía de Luis XVI; posteriormente, la revolución prometió abolir las leyes establecidas para crear un sistema igualitario, pero el triunfo de Robespierre supuso un freno a estas aspiraciones. Las promesas de libertad e igualdad sin exclusión fueron incumplidas y la verdadera paz entre iguales fracasó:

"Las leyes deben ser suplemento a la conciencia de los ciudadanos, aunque con mucha frecuencia no son nada más que cadenas opresivas o muchas veces, el último confín de la iniquidad."9

Por el contrario, para el común de la gente, las leyes son temidas por su severidad, capaces de llevar al hambriento a la guillotina por haber robado un poco de pan. Según De Grouchy, esta situación provoca el efecto contrario, y el miedo se transforma en odio y en deseo de transgredir la legalidad constantemente. La conciencia moral de los más desfavorecidos se va disolviendo paulatinamente hasta eliminar todo sentimiento de culpa y de deber a favor de un interés por ser injusto que proporcionará a lo largo de la vida muchas más satisfacciones que sinsabores. Con todo, el marco político es terrible: los poderosos están corruptos y transgreden la ley a su antojo y los pobres odian a esa minoría y aspiran a lograr cierto bienestar a partir de la violencia.

La propuesta de De Grouchy será destruir todo vestigio del Antiguo Régimen, de formas de organización primitivas y despóticas desde los cimientos para crear un marco político y social que gire en torno a la igualdad natural de los seres humanos, la solidaridad, la libertad, la democracia y leyes redactadas no en base al interés propio sino a la luz de la razón. Esta reforma política iría de la mano de una reforma moral que eliminase el egoísmo y la maldad en las personas para desarrollar pragmáticamente la solidaridad y el sentimiento de humanidad:

\footnotetext{
"Si en todos los puestos uno estuviera limitado por las leyes y obligado a actuar sólo en concordancia con ellas, y todas las posiciones fuesen conferidas por una elección general y por una elección libre, la conciencia rara vez tendría que combatir intentos criminales ni actuar contra la injusticia que la ambición puede aspirar. La moralidad podría dejar de necesitar hacer reproches a la ambición por su debilidad de carácter y cobardía en las opiniones, una ambición fundamentada en la adulación, ese arte del servilismo ante el vicio y la
}

[9] Ibíd., p. 122.

THÉMATA. Revista de Filosofía, Nº48 julio-diciembre (2013) pp.: 235-243 doi: 10.12795/themata.2013.i48.21 
vanidad, y finalmente, por toda esa corrupción de medios con demasiada frecuencia necesarios para el vicio y para esa terquedad por minar todos los fundamentos de las virtudes."10

Aquí reside la propuesta de De Grouchy sobre la paz; solo la correcta aplicación de la razón a la moral, la política y el conocimiento hará posible instaurar un periodo de armonía entre toda la humanidad. Desgraciadamente, la posibilidad de lograr este propósito fracasó cuando era más asequible: en el periodo comprendido en Francia entre 1789-1791; las críticas de la pensadora acerca de la degeneración de los principios revolucionarios de libertad, igualdad y fraternidad, que pronto fueron olvidados a favor del egoísmo, la violencia y el propio interés es manifiesta:

“(...) las instituciones sociales siguen estando muy lejos de haber alcanzado el grado más alto de utilidad que podemos obtener de las leyes penales. Y para que alcancen este grado, el pueblo debe estar dispuesto a considerar a aquellos cuyo oficio es ejecutar las leyes, arrestar al culpable y condenarlo, no como sus amos, sino únicamente como sus defensores y sus amigos."11

La realidad política francesa se ha dejado llevar por la elocuencia y el engaño de la masa ignorante. Consiguientemente, han aflorado demagogos que tan pronto han conseguido el poder, hacen todo lo posible para mantenerlo. Así, el miedo y la persecución están justificados:

"El imperio que ciertos hombres con gran magnetismo personal ejercen sobre aquellos que los escuchan o los leen y que se sienten inspirados por el carácter de sus espíritus, también está envuelto por la simpatía; este poder es el resultado de un arte, más peligroso que difícil, y que deja de ser único cuando es divulgado. Y, finalmente, saben que para casi todos los hombres, la necesidad de creer vence a la razón, razón que prescribe el creer únicamente lo que sea probado. Así, solo hace falta proponer una opinión por la fuerza, y de manera persuasiva ocultar habilidosamente todo lo que pueda convertirla en incierta; y satisfecha de haber discutido sobre la duda, la gente abraza esta opinión más ardientemente, sintiéndose más empujados por ella en la medida en que les proporciona una mayor tranquilidad."

Con todo, De Grouchy, firme defensora de la armonía y la solidaridad entre todos los pueblos se aleja claramente del optimismo condorcetiano y delinea una concepción del mundo y de los seres humanos donde la guerra dista mucho de ser una realidad próxima a desaparecer. La natural bondad humana se ha visto enturbiada por una cultura donde priman el interés propio, el poder y la fuerza por encima de la igualdad y la paz.

[10] Ibíd., p. 123.

[11] Ibíd., p. 176.

THÉMATA. Revista de Filosofía, $\mathrm{N}^{\circ} 48$ julio-diciembre (2013) pp.: 235-243

doi: 10.12795/themata.2013.i48.21 